\title{
Control of $\pi$-Radical Anion State of Porphyrin with a Polymer Matrix
}

\author{
Hiroshi Segawa, Takeo Shimidzu, ${ }^{*}$ and Ken-ichi HondA \\ Division of Molecular Engineering, Graduate School of Engineering, \\ Kyoto University, Kyoto 606, Japan
}

(Received September 28, 1987)

\begin{abstract}
The photoredox and electrochemical behavior of cationic porphyrins immobilized on Nafion was investigated using flash and continuous photolyses and modified electrode techniques. Porphyrin $\pi$-radical anions generated by photochemical and electrochemical reduction are stabilized by immobilization on Nafion. In a polymer matrix, the disproportionation of the $\pi$ radical anion is inhibited because of lowered mobility of the porphyrin.

KEY WORDS Water-Soluble Porphyrin / Nafion / Disproportionation of $\pi$-Radical Anion / Photoredox / Phlorin /
\end{abstract}

Photo-induced electron transfer reactions using porphyrin as a sensitizer have been widely studied in connection with natural photosynthesis and solar energy conversion. ${ }^{1}$ Especially, numerous attempts to photodecompose water into oxygen and hydrogen have been made by the use of water-soluble porphyrins in artificial systems. ${ }^{2}$ The reason why the water-soluble sensitizers are used for decomposition of water is that these sensitizers have good affinity to the hydrophilic reaction field and electron carriers in the water phase. However, the use of these porphyrins in water causes the shortcoming that their radicals are converted to further redox products such as chlorin, phlorin, isoporphyrin and so on. ${ }^{3}$ The further redox products are undesired species because of their irreversibility or weaker redox power than the corresponding $\pi$-radicals. ${ }^{4,5}$ In many cases, the further redox products result from the disproportionation reaction of the $\pi$ radicals. ${ }^{6}$

Recently, electrostatic effects by polyelectrolytes upon photoinduced charge separation

\footnotetext{
* To whom all correspondence should be addressed.
}

process have been actively studied by Morishima et al. ${ }^{7}$ However, polyelectrolytes may exert immobilization effects upon successive chemical reaction. Since the disproportionation reaction is bimolecular reaction of the $\pi$-radicals, it is expected that the inhibition of the disproportionation is accomplished by their electrostatic immobilization on polyelectrolytes. In this paper, we studied the redox reaction of water-soluble porphyrins immobilized on polyelectrolyte, such as Nafion. Consequently, it was found that the porphyrin $\pi$-radical anions, which were generated by photochemical and electrochemical reduction, were stabilized by immobilization on Nafion.

\section{EXPERIMENTAL}

\section{Materials}

A $5 \mathrm{wt} \%$ alcoholic aqueous solution of perfluorinate cationexchange powder (Nafion 117) was purchased from Aldrich. ${ }^{8}$ Various cationic metalloporphyrins, meso-tetrakis (4$N$-methylpyridyl)porphine metal complexes, 
were prepared according to previous literature $^{2,4,6}$ (AuTMPyP has five positive charges, ZnTMPyP and PdTMPyP have four positive charges). Other reagents were used as received (Nakarai Chem. Co and Waken Co.).

For the photo-redox reaction, a mixture of an aqueous solution of a cationic porphyrin and an appropriate equivalent weight solution of Nafion was mixed with stirring for $1 \mathrm{~h}$. The cationic porphyrins were equivalently and strongly fixed on Nafion. For electrolysis, an indium tin oxide electrode (ITO) spin-coated with Nafion 117 was used as a support of the catioic porphyrin. The coating thickness was determined by interference color method using the refractive index of Nafion $(n=1.365)$, and by SEM measurement of a cross section. After being dipped into aqueous solution of the cationic porphyrins, the electrode surface was washed with distilled water, and then the electrode was used in aqueous solution.

\section{Photolysis Procedure}

A square quartz cell connected to a pyrex tube (volume, $12 \mathrm{ml}$; optical path length, $1 \mathrm{~cm}$ ) was used as a photolysis cell. All the photolysis solutions were purged with argon. Continuous photolysis was carried out by $500 \mathrm{~W}$ Xe lamp (Ushio Electric; UXL-500-D) through an ultraviolet cut-off filter and a near-infrared cut-off filter (Toshiba, L-42 and IR-25S; $420<\lambda<700 \mathrm{~nm}$ of optical window). Flash photolysis studies were made with PHOTAL RA 412 and RA 401 instruments (pulse duration $18 \mu \mathrm{s})$. Absorption spectra were mea- sured by SM-402 Spectro-photometer (Union Giken) and MPS-2000 Spectrophotometer (Shimadzu).

\section{Electrochemical Measurement}

The electrolysis solutions were purged with argon. A three-electrode system, which consisted of platinum working and counter electrodes with saturated calomel electrode, was employed. The ITO-Nafion electrodes were also employed as working electrode for electrolysis-spectroscopy. Electrochemical measurements were performed by an NPGS-301 potentiogalvanostat and an NFG-6 function generator (Nikko Keisoku).

\section{RESULTS AND DISCUSSION}

The absorption spectral shifts of the porphyrins resulting from immobilization on Nafion are shown in Table I. In general, the aggregation of porphyrin is recognized by absorption spectral shifts, namely, the hypsochromic shift in B-band and bathochromic shift in Q-band. ${ }^{9}$ In the case of some polymers such as poly(potassium vinyl sulfate) or poly(sodium 4-styrene sulfonate), the above shifts due to stacking of the porphyrins were observed. ${ }^{10}$ In the case of Nafion, the observed shifts were not characteristic of the aggregate but of the polarity change of the surrounding matrix. It is thought that the monomeric fixation of the porphyrin in Nafion becomes feasible by the repulsion of the strong acid substituent of the backbone matrix. Since most

Table I. Absorption maxima of water-soluble porphyrins and their shifts due to fixation on Nafion

(Absorption/nm)

\begin{tabular}{|c|c|c|c|c|c|c|}
\hline \multirow{2}{*}{ Porphyrin } & \multicolumn{2}{|c|}{ Original } & \multicolumn{2}{|c|}{ Shift in colloid } & \multicolumn{2}{|c|}{ Shift in film } \\
\hline & B-Band & Q-Band & B-Band & Q-Band & B-Band & Q-Band \\
\hline ZnTMPyP & 436 & 562602 & +6 & $+3+4$ & +6 & $+2+3$ \\
\hline PdTMPyP & 414 & 522555 & +4 & +5 & +7 & +7 \\
\hline RuTMPyP(CO) & 420 & 536 & +4 & +3 & +2 & +6 \\
\hline AuTMPyP(Cl) & 406 & 481523558 & -1 & $\begin{array}{lll}-1 & -2 & -3\end{array}$ & \multicolumn{2}{|c|}{ Trace } \\
\hline $\operatorname{MnTMPyP}(\mathrm{Cl})$ & 463 & 506562 & Trace & +1 & \multicolumn{2}{|c|}{ Trace } \\
\hline
\end{tabular}


of the shifts were bathochromic, it was suggested that the porphyrin was immobilized in the hydrophilic domain of Nafion. The bathochromic shift was also observed in mono-cationic AuTPyP bound in Nafion film (402, $520,552, \rightarrow 409,524,558 \mathrm{~nm})$.

AuTMPyP is photo-reduced with various sacrificial reductants and produce its $\pi$-radical anion $\left(\lambda_{\max }=638,780\right.$ shoulder and $\left.935 \mathrm{~nm}\right)$ which is immediately converted to the corresponding phlorin $\left(\lambda_{\max }=475\right.$ and $\left.770 \mathrm{~nm}\right)$ via disproportionation. $^{6 c}$ In the absence of Nafion, AuTMPyP $\left(5.6 \times 10^{-5} \mathrm{~mol} \mathrm{dm}^{-3}\right)$ was photo-reduced to phlorin with EDTA $(1.1 \times$ $10^{-2} \mathrm{moldm}^{-3}$ ) in steady state irradiation at pH 7.5 as shown in Figure. 1. In the initial stage of the photo-reduction, the absorption shoulder of $\pi$-radical anion was observed at $630 \mathrm{~nm}$ with $770 \mathrm{~nm}$ absorption of phlorin, but the shoulder disappeared within $90 \mathrm{~s}$. By the addition of 2.9 equivalents of Nafion for the charges of AuTMPyP in the same component solution at $\mathrm{pH} 7.5$, the $\pi$-radical anion was remarkably stabilized. As shown in Figure 2 , the only absorption of $\pi$-radical anion at $633 \mathrm{~nm}$ appeared with steady state irradiation within at least $4080 \mathrm{~s}$. The spectral changes upon steady state irradiation exhibited distinct isosbestic points, thus indicating clean reduction without successive reactions. The same results were obtained for other sacrificial reductants such as triethanolamine (TEA).

The stabilization of the $\pi$-radical anion depended largely on Nafion concentration (Table II). The molar ratio of phlorin per $\pi$-radical anion went down with increasing content of Nafion, and then became zero in the presence of almost equivalent Nafion. When the ionic strength in the solution increased by the addition of neutral salt, the porphyrin was excluded from the Nafion matrix so that it was immediately converted to phlorin in the bulk solution. These observations imply that the equivalent immobilization needs to stabilize $\pi$ radical anion.

The spectral change during potentiostatic

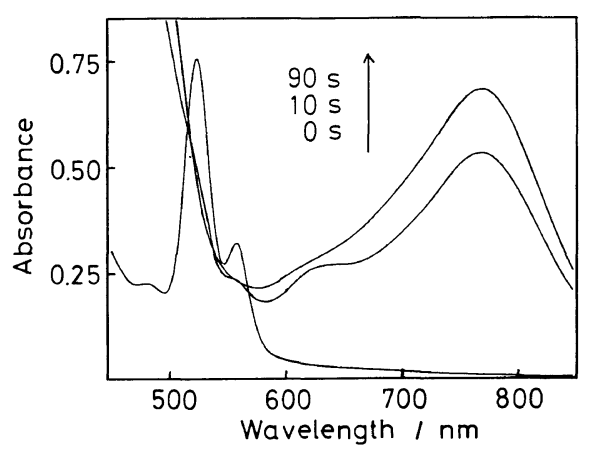

Figure 1. The time course of absorption spectra in the photoreduction of AuTMPyP $\left(5.0 \times 10^{-5} \mathrm{moldm}^{-3}\right)$ with EDTA $\left(1.1 \times 10^{-2} \mathrm{moldm}^{-3}\right)$ at $\mathrm{pH} 7.5$ in the absence of Nafion.

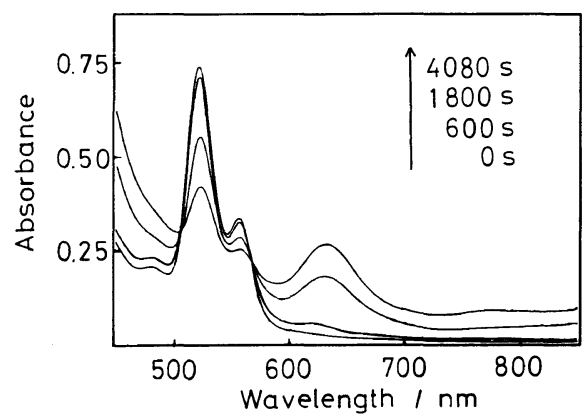

Figure 2. The time course of absorption spectra in the photoreduction of AuTMPyP $\left(5.0 \times 10^{-5} \mathrm{moldm}^{-3}\right)$ with EDTA $\left(1.1 \times 10^{-2} \mathrm{moldm}^{-3}\right)$ at $\mathrm{pH} 7.5$ in the presence of 2.9 equivalent of Nafion.

Table II. Concentration effects of Nafion on photoreduction of AuTMPyP

\begin{tabular}{ccc}
\hline $\begin{array}{c}\text { Concentration of } \\
\text { Nafion }\end{array}$ & $\begin{array}{c}\text { Equivalent to } \\
\text { porphyrin }\end{array}$ & $\begin{array}{c}\text { Phlorin/ } \pi \text {-radical } \\
\text { anion }^{\mathrm{a}}\end{array}$ \\
\hline $0\left(\mathrm{wt}^{\mathrm{o}} \mathrm{o}\right)$ & 0.00 & 0.44 \\
$5.0 \times 10^{-3}$ & 0.14 & 0.41 \\
$2.5 \times 10^{-2}$ & 0.72 & 0.00 \\
$5.0 \times 10^{-2}$ & 1.44 & 0.00 \\
\hline
\end{tabular}

Concentration of AuTMPyP was $0.05 \mathrm{mmoll}^{-1}$. Triethanolamine $\left(0.2 \mathrm{moll}^{-1}\right)$ was used as sacrificial electron donor. Visible-light irradiation $(420-700 \mathrm{~nm})$ was performed by $500 \mathrm{~W}$ Xe lamp for $10 \mathrm{~min}$ at $\mathrm{pH} 8.8$.

a Molar ratio.

reduction $(-600 \mathrm{mV}$ vs. SCE) of AuTMPyP using Nafion-ITO electrode is shown in Figure 3. In homogeneous aqueous solution at 


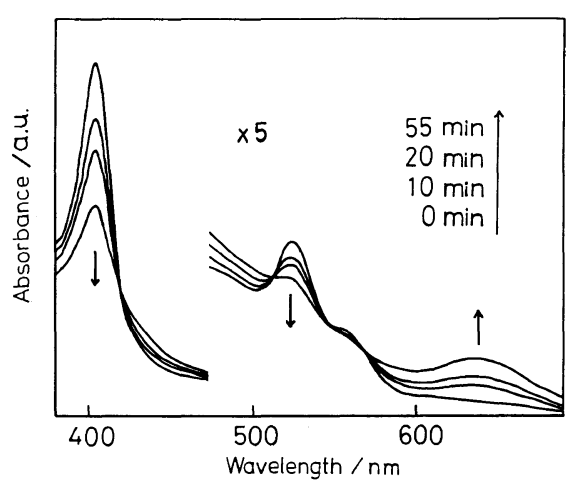

Figure 3. The absorption spectral change of AuTMPyP fixed on Nafion-ITO electrode during potentiostatic electrolysis in aqueous solution. Electrolysis were performed at $-600 \mathrm{mV} v$ s. SCE in $0.1 \mathrm{~mol} \mathrm{dm}^{-3}$ $\mathrm{Na}_{2} \mathrm{SO}_{4}$ using $0.52 \mu \mathrm{m}$ of Nafion film electrode.

$\mathrm{pH}<9$, the potentiostatic reduction of AuTMPyP at $-600 \mathrm{mV}$ resulted in its phlorin through the disproportionation of the $\pi$-radical anion. ${ }^{4 b}$ However, AuTMPyP fixed on Nafion-ITO electrode was selectively reduced to its $\pi$-radical anion $\left(\lambda_{\max }=643 \mathrm{~nm}\right)$ under a potentiostatic condition at $-600 \mathrm{mV}$ regardless of bulk acidity. The $\pi$-radical anion was completely oxidized back to native AuTMPyP by the potentiostatic oxidation at $0 \mathrm{mV}$. It was shown that the disproportionation reaction of the $\pi$-radical anion was also inhibited by the immobilization on Nafion film. The apparent diffusion constant of AuTMPyP immobilized on Nafion was measured by chronoabsorptmetry using this modified electrode (see APPENDIX). The obtained apparent diffusion constant of $2.3 \times 10^{-13} \mathrm{~cm}^{2} \mathrm{~s}^{-1}$ is fairly small compared with diffusion constant of $1.6 \times 10^{-5} \mathrm{~cm}^{-2} \mathrm{~s}^{-1}$ in Nafion-free aqueous solution, obtained by cyclic voltammetry. Thus, it is clear that the mobility of porphyrin markedly decreases by immobilization on Nafion.

The pulsed irradiation of a solution containing $0.20 \mathrm{mM}$ AuTMPyP and $0.010 \mathrm{M}$ EDTA at $\mathrm{pH} 4$ resulted in the formation of $\pi$-radical anion of AuTMPyP in less than $1 \mathrm{~ms}$. The absorption monitored at $640 \mathrm{~nm}$ decays via

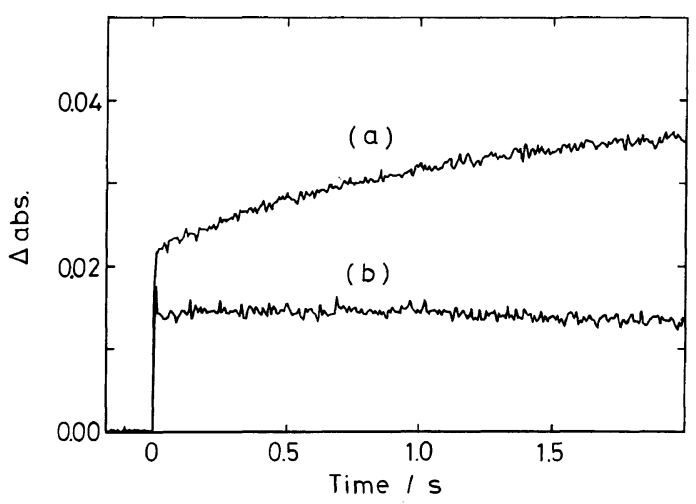

Figure 4. Growth of phlorin monitored at $770 \mathrm{~nm}$ after photoreduction of AuTMPyP $\left(2.0 \times 10^{-4} \mathrm{~mol} \mathrm{dm}^{-3}\right)$ by flash photolysis at $\mathrm{pH} 4$ with EDTA $\left(1.0 \times 10^{-2}\right.$ mol dm ${ }^{-3}$ ). (a) absence of Nafion; (b) presence of 2.0 equivalent of Nafion.

second-order kinetics ${ }^{6 \mathrm{c}}$ with formation of an absorption with maxima in the $770 \mathrm{~nm}$ region (Figure 4); the spectrum is characteristic of phlorin of AuTMPyP. The second-order decay of the $640 \mathrm{~nm}$ absorption and the complementary growth of $770 \mathrm{~nm}$ absorption indicated the $\pi$-radical anion of AuTMPyP to be converted to the corresponding phlorin via disproportionation. ${ }^{6 \mathrm{c}}$ The transient absorption decay and growth depend on concentration of Nafion. The absorption growth at $770 \mathrm{~nm}$ is inhibited in the presence of 2.0 equivalents of Nafion. This observation also implies that the. disproportionation of the $\pi$-radical anion is inhibited by the addition of Nafion.

After the steady state photoreduction of AuTMPyP, PdTMPyP, and ZnTMPyP for $10 \mathrm{~min}$, the restoration yields for reoxidation by $\mathrm{O}_{2}$ were measured in the absence and presence of Nafion as shown in Table III. The photo-generated $\pi$-radical anions were completely re-oxidized back to the native porphyrin by $\mathrm{O}_{2}{ }^{4}$ In the case of homogeneous systems, however, the additional formation of phlorin and/or chlorin caused the restoration ratio to decrease. The formation of such undesired successive products was considerably inhibited by colloidal Nafion systems. The restoration yield reached 1.00 in the best case of 
Table III. The restoration ratio for reoxidation after photoreduction

\begin{tabular}{lll}
\hline Porphyrin & In Nafion colloid & In homogeneous aqueous solution \\
\hline AuTMPyP & 1.00 & 0.23 (Phlorin generation) \\
PdTMPyP & 0.96 (Chlorin generation) & 0.53 (Chlorin and phlorin generation) \\
ZnTMPyP & 0.5 (Decomposition) & 0.0 (Decomposition) \\
\hline
\end{tabular}

All solutions were kept at $\mathrm{pH} 7.0$ with phosphate buffer. Concentration of porphyrin was $0.05 \mathrm{mmoll}^{-1}$. Triethanolamine was used as a sacrificial electron donor and the concentrations were $0.8 \mathrm{moll}^{-1}$ in Nafion and $0.02 \mathrm{moll}^{-1}$ in homogeneous aqueous solution. The photolysis solutions were irradiated for $10 \mathrm{~min}$ with $500 \mathrm{~W} \mathrm{Xe}$ lamp. Then the reoxidation was carried out using $\mathrm{O}_{2}$. The by-products which diminished the durability of the redox cycle are shown in parentheses.

AuTMPyP.

\section{CONCLUSIONS}

The mobilities of the porphyrins decreased in the polyelectrolyte matrix, so that the disproportionation caused by bimolecular reaction of the $\pi$-radical anions of the porphyrins during photochemical and electrochemical reduction is depressed, and consequently generation of the phlorin and the chlorin is inhibited. These $\pi$-radicals have strong redox power and high reversibility, so that the simpie redox pathways via these $\pi$-radicals are considered to be favorable for effective solar energy conversion Establishment of an effective solar energy conversion system using this method is in progress.

\section{APPENDIX}

The total amount of the fixed porphyrin was proportional to the Nafion membrane thickness under the present fixation conditions. Therefore, it was considered that the porphyrins should be uniformly fixed on Nafion although microscopically heterogeneous structure of Nafion was pointed out. The apparent diffusion constant of the porphyrin bound in Nafion was approximately determined according to homogeneous Cottrell-type analysis. The Integrated Cottrell equation is

$$
Q_{i}=2 A F C_{0} D_{\mathrm{app}}^{1 / 2} t_{i}^{1 / 2} \pi^{-1 / 2}
$$

$Q_{i}$, amount of electricity from $t=0$ to $t=t_{i}$; $A$, area of electrode; $C_{0}$, concentration of the reactant; $D_{\text {app }}$, apparent diffusion constant of the reactant.

at a diffusion layer thickness $\delta \ll$ the membrane thickness $d$. When $Q_{i}$ is normalized by the amount of electricity for the complete reduction of the fixed porphyrins $Q_{\infty}$, the molar fraction $\left(f_{i}\right)$ at $t_{i}$ is

$$
\begin{aligned}
f_{i} & =\frac{Q_{i}}{Q_{\infty}}=\frac{2 A F C_{0} D_{\mathrm{app}}{ }^{1 / 2} t_{i}^{1 / 2} \pi^{-1 / 2}}{F C_{0} A d} \\
& =2 D_{\mathrm{app}}{ }^{1 / 2} t_{i}^{1 / 2} \pi^{-1 / 2} d^{-1}
\end{aligned}
$$

Equation 2 should hold when $\delta$ is less than half $d$. Since $\delta$ is given by $\left(\pi D_{\text {app }} t\right)^{1 / 2}$, the molar fraction at $\delta=d / 2$ is $1 / \pi$. Therefore, the condition at $f=1 / \pi$ means $\left(\pi D_{\text {app }} t_{1}\right)^{1 / 2}=d / 2$. This $d-t^{1 / 2}$ plot allows determination of $D_{\mathrm{app}}$.

Acknowledgement. This work was partly supported by a Grant-in-Aid for Scientific Research from the Ministry of Education, Science, and Culture of Japan.

\section{REFERENCES}

1. J. Kiwi, K. Kalyanasundaram, and M. Grätzel, Struct. Bonding (Berlin), 49, 37 (1982).

2. (a) A. Harriman, G. Porter, and M. Richoux, $J$. Chem. Soc., Faraday Trans. 2, 77, 833 (1981).

(b) K. Kalyanasundaram and M. Grätzel, Helv. Chim. Acta, 62, 1345 (1979).

(c) T. Shimidzu, T. Iyoda, Y. Koide, and N. Kanda, Nouv. J. Chim., 7, 21 (1983).

3. (a) G. L. Closs and L. E. Closs, J. Am. Chem. Soc., 
85, 818 (1963).

(b) D. Dolphin, R. H. Felton, D. C. Borg, and J. Fajer, J. Am. Chem. Soc., 92,743 (1970).

4. (a) A. Harriman, G. Porter, and P. Walters, J. Chem. Soc., Faraday Trans. 1, 79, 1335 (1983).

(b) T. Shimidzu, T. Iyoda, H. Segawa, and K. Honda, Nouv. J. Chim., 10, 213 (1986).

5. J. G. Lawese and G. S. Wilson, J. Electrochem. Soc., 8, 1041 (1972).

6. (a) M. Richoux, P. Neta, A. Harriman, S. Baral, and P. Hambright, J. Phys. Chem., 90, 2462 (1986).

(b) A. Harriman, M. Richoux, and P. Neta, J. Phys. Chem., 87, 4957 (1983).

(c) T. Shimidzu, H. Segawa, T. Iyoda, and K. Honda, J. Chem. Soc., Faraday Trans. 2, in press.
7. Y. Morishima, Y. Itoh, S. Nozakura, and T. Ohno, Macromolecules, 17, 2264 (1984).

8. N. Kakuta, J. M. White, A. Campion, A. J. Bard, M. A. Fox, and S. E. Webber, J. Phys. Chem., 89, 48 (1985).

9. (a) R. F. Pasternack, L. Francesconi, D. Raff, and E. Spiro, Inorg. Chem., 12, 2606 (1973).

(b) T. Shimidzu and T. Iyoda, Chem. Lett., 853 (1981).

(c) J. A. Shelnutt, M. M. Dobry, and J. D. Satterlee, J. Phys. Chem., 88, 4980 (1984).

(d) E. Ojadi, R. Selzer, and H. Linschitz, J. Am. Chem. Soc., 107, 7783 (1985).

10. T. Shimidzu and K. Fukui, Ann. Rep. Chem. Fibers. Jpn., 38, 93 (1981). 